\title{
Fundamentos éticos na tomada de decisão de discentes de fisioterapia
}

Talita Leite Ladeira(a)

Aluísio Gomes da Silva Junior(b)

Lilian Koifman ${ }^{(\mathrm{c})}$

Ladeira TL, Silva Junior AG, Koifman L. Ethical foundations of decision-making in physical therapy students. Interface (Botucatu). 2017; 21(62):675-85.

Clinical decision-making should encompass technical and ethical aspects. It is necessary to recognize the ethical conflicts and to understand the moral values involved in order to provide efficient responses to ethical issues present in practice. This descriptive qualitative study aimed to understand the perception of students of physical therapy about the moral values that should guide care actions and to identify the ethical foundations of the decision-making process. The study included 13 students of physical therapy of a Federal University in Brazil. The study applied individual semi-structured interviews proposing an hypothetical moral dilemma correlated with professional practice. We noted deficiency in the bioethical reference framework of students exposed to conflicts. Thus, there is a need to rethink the professional education in order to promote a more conscious and responsive healthcare decision-making.

Keywords: Bioethics. Decision-making. Physical therapy.
A tomada de decisão clínica deve abranger aspectos técnicos e éticos. É preciso reconhecer os conflitos éticos e compreender os valores morais envolvidos, para, enfim, fornecer respostas eficientes às questões éticas presentes na práxis. Este estudo qualitativo descritivo teve como objetivos compreender a percepção dos discentes de fisioterapia sobre os valores morais que devem pautar as ações de cuidado e identificar os fundamentos éticos que embasam a tomada de decisões. Participaram da investigação 13 discentes de fisioterapia de uma Universidade Federal brasileira. Foram realizadas entrevistas semiestruturadas individuais, com aplicação de um dilema moral hipotético correlacionado com a prática profissional. Observamos deficiência no referencial bioético dos discentes frente aos conflitos expostos. Assim, há necessidade de repensarmos a formação, a fim de fomentarmos tomada de decisões em saúde mais conscientes e resolutivas.

Palavras-chave: Bioética. Tomada de decisões. Fisioterapia.

\footnotetext{
(a) Curso de Fisioterapia, Centro Universitário Estácio Juiz de Fora. Av. Pres. João Goulart, 600, Cruzeiro do Sul. Juiz de Fora, MG, Brasil. 36030-142. talitaladeira@ yahoo.com.br (b,c) Departamento de Planejamento em Saúde, Instituto de Saúde Coletiva, Universidade Federal Fluminense. Niterói, RJ, Brasil. agsilvaj@gmail.com; liliankoifman@id.uff.br
} 


\section{Introdução}

A atuação do fisioterapeuta surgiu em um contexto de grandes guerras mundiais e grande industrialização, o que contribuiu para o primeiro perfil profissional, caracterizado pela missão de atenuar e reabilitar os organismos lesados fisicamente.

Regulamentada no Brasil em 1969, a profissão teve suas raízes históricas vinculadas ao modelo biomédico, cartesiano ${ }^{(d)}$, com uma visão reducionista ${ }^{2-5}$. Assim como os demais profissionais de saúde, o fisioterapeuta está inserido em um contexto de formação focado na doença, mas de forma mais acentuada, já que é visto como "o profissional da reabilitação", atuando, exclusivamente, quando a doença, lesão ou disfunção já foi estabelecida ${ }^{6}$.

Ao longo dos anos, a fisioterapia solidificou-se como profissão de saúde e ampliou seus campos de intervenção. Hoje, os fisioterapeutas dispõem de autonomia e possuem grandes responsabilidades dentro das equipes interdisciplinares. Participam, cada vez mais, das tomadas de decisão, trazendo, para si, a problemática dos dilemas e das responsabilidades éticas mais complexas no exercício da profissão ${ }^{7}$. Estão expostos a uma variedade de conflitos éticos que podem estar presentes na práxis, gerando a necessidade premente de que sejam contemplados conteúdos formativos voltados para tais questões éticas. A profissão requer um desenvolvimento moral consistente para encarar os desafios e as mudanças enfrentadas ${ }^{8}$.

Segundo as Diretrizes Curriculares da graduação do curso de Fisioterapia, o perfil desejável do egresso é:

Fisioterapeuta, com formação generalista, humanista, crítica e reflexiva, capacitado para: atuar em todos os níveis de atenção à saúde, com base no rigor científico e intelectual. Detém visão ampla e global, respeitando os princípios éticos/bioéticos, e culturais do indivíduo e da coletividade. ${ }^{9}$ (p. 22)

Certamente, nos últimos anos, houve um significativo aumento do reconhecimento da bioética como conteúdo fundamental para uma formação profissional no Brasil ${ }^{10}$. Entretanto, no curso de fisioterapia, a aproximação com a bioética ainda é muito incipiente ${ }^{10}$. As temáticas que envolvem as duas áreas estiveram, ao longo da história da profissão nacional, fundamentadas em conceitos deontológicos, limitadas ao código de ética profissional e aos aspectos legais ${ }^{10,11}$.

Em relação à produção científica, um levantamento bibliográfico de $2013^{10}$ aponta que ainda nos encontramos no nível primário do desenvolvimento da reflexão bioética em fisioterapia. Por meio da busca pelos descritores "fisioterapia" e "bioética" e seus derivados, Lorenzo e Bueno encontraram somente cinco artigos nacionais publicados em revistas indexadas de 2000 a 2011. O cenário também retrata que há "deficiências conceituais, distanciamento das teorias mais modernas e dos modelos desenvolvidos no Brasil e falta de consideração dos contextos socioculturais e econômicos como elementos que influenciam a geração de conflitos"10 (p. 763).

As discussões nacionais sobre as questões éticas e a sua relação com a fisioterapia emergiram apenas a partir de 2002, e, além da carência de estudos, percebe-se a ausência da discussão sobre essa temática entre fisioterapeutas ${ }^{11}$.

Nesse contexto emergem os objetivos desta pesquisa: (1) compreender a percepção dos discentes de fisioterapia sobre os valores morais que devem pautar as ações de cuidado, e (2) identificar quais os fundamentos éticos que embasam a tomada de decisões.

(d) Refere-se ao modelo proposto pelo filósofo francês René Descartes (1595-1650), que propõe a divisão do todo em partes e as estuda em separado, isoladamente ${ }^{1}$. 


\section{Percurso metodológico}

Trata-se de uma pesquisa empírica de abordagem qualitativa, no escopo da ética descritiva, desenvolvida na Faculdade de Fisioterapia de uma Universidade Federal brasileira.

Foi aprovada pelo Comitê de Ética em Pesquisa da Faculdade de Medicina da Universidade Federal Fluminense/FM/UFF/HU Antônio Pedro, obedecendo determinações da Resolução CNS/MS 466/12 ${ }^{12}$.

Participaram do estudo 13 discentes de fisioterapia, do $9^{\circ}$ e $10^{\circ}$ períodos do curso, sendo que todos assinaram o Termo de Consentimento Livre e Esclarecido. Para garantia do anonimato, foram caracterizados pela letra " $D$ " acrescida de numeração. Não houve nenhuma intencionalidade de delineação amostral por parte da pesquisadora, e a amostragem foi por saturação.

Os critérios de inclusão foram a disponibilidade e aceite em participar da pesquisa, e a necessidade de estarem cumprindo o estágio curricular. O critério de exclusão foi a falta de experiência prévia em outro local de estágio.

Foram realizadas entrevistas semiestruturadas individuais, com aplicação de um dilema moral hipotético, as quais aconteceram no ambulatório de fisioterapia da faculdade, no mês de março de 2014.

A situação expõe um conflito referente à práxis fisioterapêutica, com intuito de aproximar os discentes da realidade e estimular reflexões para a tomada de decisão mais pertinente, segundo seus próprios valores.

A situação foi descrita em terceira pessoa, mencionando o curso de ação elaborado pelos profissionais. O dilema foi narrado pela pesquisadora e, em seguida, procuramos explorar e compreender as percepções frente à seguinte situação:

"Sr. M., sexo masculino, 65 anos de idade, lúcido e orientado, está internado na Unidade de Terapia Intensiva (UTI), com diagnóstico de Insuficiência Respiratória Aguda (IRA). O mesmo faz uso de ventilação não-invasiva, por máscara facial.

Desde sua admissão na UTI, o paciente mostrou-se ansioso e preocupado com a possibilidade de ser conectado ao ventilador mecânico, sendo taxativo que não gostaria de ser submetido a este procedimento.

Após dois meses de internação, a gasometria arterial e o hemograma começam a apresentar alterações progressivas, com quadro de taquipneia e uso exacerbado da musculatura acessória. O paciente também apresenta diminuição do estado de consciência e confusão mental.

Após análise do quadro clínico pela equipe multidisciplinar, levanta-se a possibilidade de iniciar a ventilação mecânica (VM), a fim de diminuir o desconforto respiratório e restabelecer as trocas gasosas. É estabelecido um embate entre os profissionais. Eles hesitam, mas por fim optam por intubar o paciente".

As entrevistas foram gravadas e transcritas. Logo após, foram realizadas leituras em profundidade de todo o material, iniciando a sistematização e categorização que emergiu das falas dos participantes e seguiu o critério semântico. Para análise dos dados, utilizamos a análise de conteúdo de Bardin ${ }^{13}$. Todo o processo de entrevistas e análise dos dados foi realizado por somente uma pesquisadora.

\section{Resultados e discussão}

De acordo com o perfil dos discentes de fisioterapia participantes, 12 cursavam o $10^{\circ}$ período e um cursava o $9^{\circ}$ período. Somente um era do sexo masculino, e a média de idade foi de 24,5 anos.

A seguir, apresentaremos como os mesmos posicionaram-se mediante o dilema, apontando os conflitos de valores, os problemas éticos fundamentais, bem como os cursos de ações propostos e suas tendências, destacando falas mais representativas.

Inicialmente, após leitura, podemos depreender que, de um modo geral, a situação exposta gerou desconforto, preocupação e dúvida, sendo reconhecida como conflito ético pelos discentes, exceto D6. 


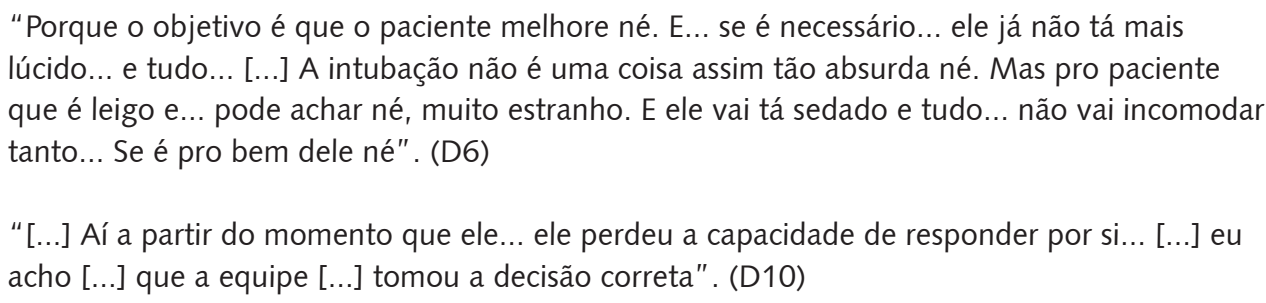

Ao serem questionados se concordam ou não com a decisão tomada pelos profissionais, houve unanimidade na defesa da intubação, sendo justificada por muitos, em decorrência da inconsciência do paciente, logo incapacidade de decidir, e pela necessidade do procedimento.

Além da inconsciência, D6 justifica a intubação por meio da finalidade de melhora do paciente. Percebemos, também, indícios de desqualificação do outro, na medida em que é considerado leigo e, dessa forma, parece não entender a necessidade da intervenção. Acredita, ainda, que por estar sedado, não haveria grandes malefícios.

Para Beauchamp e Childress ${ }^{14}$, realizar um procedimento em um paciente incapaz, sendo que, enquanto capaz, relatou recusa, é uma violação à autonomia do mesmo, desrespeito e insulto à pessoa.

Com base nas linhas argumentativas referentes ao que mencionaram ser ideal nesse caso, procuramos abordar quais foram os valores éticos e morais, bem como princípios éticos norteadores, que lhes motivaram a optar a favor ou contra a intubação. Vale ressaltar que, em alguns casos, percebemos presença de argumentações multivariadas complementares, representadas por mais de uma perspectiva que justificasse a tomada de decisão.

Para grande parte dos participantes, essa tomada de decisão foi considerada difícil. Há reconhecimento unânime do princípio bioético da autonomia, que surge como valor a prima facie. Em contrapartida, foram expostos outros valores em conflito, os quais serviram para embasar as tomadas de decisão frente ao dilema exposto. Tais conflitos de valores resumiram-se à: autonomia versus manutenção da vida, autonomia versus beneficência, autonomia versus não maleficência, autonomia do paciente versus autonomia da equipe, autonomia versus valorização de dados técnicos.

O conflito entre respeito à autonomia do paciente e preocupação com a manutenção de sua vida foi, de maneira geral, citado pela maioria dos entrevistados, sendo, a última, relevante para a resolução do dilema proposto, por parte de muitos discentes.

“[...] Mas ao mesmo tempo a gente também quer lutar pela vida do paciente... é o nosso papel lutar pela vida do paciente. [...] Nesse embate de vida ou morte temos que estabelecer a vida de qualquer jeito". (D5)

Conforme exposto, passar por cima da vontade do paciente é algo que gera um conflito ético, entretanto, é justificado pela necessidade imperativa de manter a vida, mesmo que, para isso, custe impor um tratamento a alguém que não deseja se submeter a ele.

Tal concepção corrobora com o ponto de vista moral que embasa o Princípio da Sacralidade da Vida (PSV), o qual afirma que "a vida é sempre digna de ser vivida, ou seja, estar vivo é sempre um bem, independente das condições em que a existência se apresente"15 (p. 24). Existe a premissa absoluta de que a vida consiste em um bem, possuindo, assim, um estatuto sagrado, não podendo ser interrompida, nem mesmo por expressa vontade de seu detentor ${ }^{15}$. Esse princípio é discutido amplamente na bioética, sendo utilizado para reafirmar as discussões contrárias à eutanásia.

Sobre essa condição da vida como um bem em si mesmo, Siqueira Batista ${ }^{15}$ defende que a competência de julgar sobre a vida cabe ao próprio titular da existência. Acreditamos que atribuir nossos valores à vida de outrem é, acima de tudo, ferir a alteridade, na medida em que não somos capazes de nos colocar no lugar do outro, com base no diálogo e valorização das diferenças existentes. Deve haver uma necessidade moral premente de responsabilizarmos pelos relacionamentos com base no reconhecimento no contexto alheio, e não, baseados apenas em nossos imperativos morais. Isso requer o saber ouvir, indo mais além, o saber se relacionar, sem julgamentos, aberto às diferenças. 
Em contrapartida, um dos discentes faz referência não só à vida em si, mas que ela tenha qualidade, com o mínimo de prejuízo possível. A importância da tomada de decisão a favor da intubação está na sobrevida do paciente, somada à minimização dos riscos e danos e maior benefício (beneficência).

“[...] você pode até esperar mais um dia e depois conseguir reverter o caso, mas não consegue reverter tudo, porque podem ter microlesões. [...] Você pode conseguir fazer com que ele sobreviva, mas só que ele pode ter mais prejuízo. A meta é manter o paciente vivo no melhor estado possível. Não esperar [...] até o último momento, quando ele tá quase... aí que vai resolver? Não. Será que não seria mais benéfico pra ele a gente intubar antes?" (D4)

Consoante explicitado, o ato desempenhado no intuito de minimizar prejuízos é compreendido como ato intuitivo de fazer o bem. Assim, o discente acredita que a demora na decisão por intubar pode diminuir a chance de recuperação com o máximo de benefícios e mínimo de prejuízos. Por conseguinte, seria mais benéfico para o paciente que ele fosse submetido ao procedimento o quanto antes. O objetivo maior passa a ser a vida, mas que o paciente viva qualitativamente bem.

Esta perspectiva corrobora com a proposta do Princípio da Qualidade de Vida (PQV). Este princípio é antagônico ao PSV e desconsidera o valor intrínseco da vida, que passa a ter sentido somente se é provida de um certo número e grau de qualidades histórica e socioculturalmente construídas, e aceitas pelo titular de uma vida particular ${ }^{16}$.

Em muitas falas, percebemos que a manutenção da vida do paciente parece estar interligada com o dever de natureza hipocrática do profissional de saúde. D10 menciona que seria difícil lidar com a situação de deixar de fazer algo que poderia ter sido utilizado para salvar a vida.

\begin{abstract}
“Ah... eu acho que é muito assim... a visão de que a gente sempre tem que oferecer... assim... o máximo de recursos... de tratamento, de condutas que pudessem, de alguma forma, dar todas as chances daquele paciente continuar vivendo. [...] Mesmo que ele deixasse por escrito, tudo certinho... e... os profissionais [...] não fizessem a intubação, eu acho que também seria muito complicado saber que algo a mais poderia ter sido feito, mas o paciente não quis". (D10)
\end{abstract}

“[...] Mas aí entra em conflito com tudo o que a gente aprendeu, com tudo que a gente sabe, com tudo que a gente pode dispor de melhor pra pessoa... entendeu?!" (D2)

Nesse âmbito, podemos perceber, também, um conflito entre a autonomia do paciente e a autonomia do profissional, que acontece no momento em que o paciente não pode mais decidir por si, gerando um embate para os profissionais entre: o que o paciente permite que faça com ele versus o que a equipe deseja fazer pelo paciente.

"Porque a gente sempre quer dar o melhor né. Então a gente sempre considera que o nosso saber é o melhor pra pessoa". (D2)

O embate entre respeitar a autonomia do paciente ou garantir a melhora da condição clínica (beneficência) - autonomia versus beneficência - parece ser justificado pela necessidade de melhorar seu quadro clínico. Outro argumento muito defendido pelos discentes de fisioterapia a favor da intubação baseia-se no princípio bioético da beneficência.

"O benefício que o paciente vai ter depois né. Se for analisado, realmente isso vai ser bom para o paciente, aí eu acho que isso justifica". (D12)

“[...] pelo quadro clínico do paciente e pra ele melhorar, porque se não ele ia entrar... ele ia falecer, provavelmente. [...]". (D3) 
Em caso de risco de morte, há tendência de refutação da autonomia em favor da beneficência. Muitas vezes, o respeito à mesma é menos importante do que manifestações de beneficência ${ }^{14}$.

Na nossa visão, existe um risco de justificarmos as ações mediante o imperativo de fazer o bem a qualquer custo. Sob tal ponto de vista, podemos abrir prerrogativas para situações injustas, na medida em que, pelo nome do bem, podemos deliberar pela vida do outro segundo nossa própria consciência, o que poderia gerar ações paternalistas. Por serem responsáveis por bens primários, já que têm em suas mãos o mais precioso da vida das pessoas - vida e morte -, os profissionais passam a ter o poder e a autoridade para definir o que é benéfico para as pessoas ${ }^{17}$.

Tal prerrogativa está alicerçada em duas falácias: nega a autonomia do paciente para definir o que quer e atribui, ao profissional, a obrigação de definir o benefício ${ }^{17}$. Conforme preconizado por Gracia ${ }^{17}$, defendemos que, nas ações de saúde, deveriam ser os direitos dos cidadãos - agentes sociais-- que definissem os deveres dos profissionais, e não, o contrário.

A percepção de redução de riscos e danos também pode ser observada nos trechos que se seguem:

“[...] o fato dele tá... dele ter piorado né, os sinais dele assim, terem piorado... o quadro clínico ter piorado e também o fato dele ter entrado em coma, dele tá com confusão mental. [...]

Seria para evitar que ele piorasse cada vez mais. [...] Eu acho que quando intuba um paciente, diminui a chance de morrer né... assim... ele fica estável"

Muitos mencionaram a possibilidade de causar danos e a preocupação com a possível piora do quadro clínico do paciente, caso a intubação não fosse realizada. Assim, o valor da não maleficência é visto pela execução do procedimento.

\footnotetext{
"Tem os pontos positivos, tem os pontos negativos. Além dessa decisão dele, que ele chegou consciente, não querendo. A gente tem que respeitar isso. Só que isso tem que tomar cuidado pra não ir contra essa... eh... pra causar malefício para o paciente". (D7)
}

Percebemos que esse enfoque aparece interligado à necessidade de evitar a morte - visto como mal maior -, logo, salvaguardar a vida do paciente, como podemos perceber nas falas seguintes sobre o que poderia ter levado a equipe a decidir pela intubação.

“O quadro do paciente né. Já está internado há tanto tempo e só tá piorando né... aí o quadro dele, pra não ficar pior...". (D6)

"Eu acho que é esse fato que eu falei, de tá com risco de morrer". (D1)

Na perspectiva valorativa, o profissional teria um dever, e o seu não cumprimento causaria dano a terceiros, podendo culminar em morte. Assim, esse dano ocorreria após falha do profissional ao cumprir esse dever moral ${ }^{14}$.

Na bioética, não há unanimidade sobre a diferenciação entre os princípios da não maleficência e beneficência. Contudo, "combiná-las num mesmo princípio obscurece distinções relevantes"14 (p. 210).

Beauchamp e Childress ${ }^{14}$ compreendem que a prevenção de danos e a eliminação de condições prejudiciais relacionam-se à beneficência, e não à não maleficência, já que requerem atos positivos de beneficiar o outro, e, não, simplesmente se abster de realizar atos nocivos. Entretanto, percebemos, mediante o que foi exposto, que o fato de evitar a piora - risco de dano - do paciente parece estar mais ligado à diminuição de chance de morte - "mal maior" -, do que, necessariamente, obrigação de fazer o bem.

A referência aos aspectos técnicos e biológicos para a tomada de decisão clínica também foi constante nas argumentações. Os estudantes, de uma maneira geral, mencionaram que levariam em consideração os dados clínicos apresentados pelo paciente, o prognóstico e a necessidade fisiológica da ventilação mecânica, desconsiderando as questões éticas envolvidas no caso. Isso reforça o reducionismo do problema ético no âmbito técnico ${ }^{18}$. 
"Acredito que, claro, os sinais clínicos do paciente, os dados do exame físico, de tudo, gasometria e priorizando realmente o bem estar dele, que ele saia da UTI bem". (D7)

Outra conduta que pareceu defensável para os discentes refere-se ao conhecimento acerca "do que é melhor para o paciente", embora exista o reconhecimento de que é importante considerar a vontade do mesmo. Há clara supervalorização dos conhecimentos que a equipe detém com relação ao que é estipulado como sendo "o melhor" para o paciente.

“[...] E mostrar pra ele também que a gente não passou por cima da vontade dele. A gente levou em consideração... assim... a gente equipe, a gente levou em consideração o que que você queria, o seu medo, a sua ansiedade, mas... o melhor pra você foi isso que a gente resolveu. (D4)

Nessa visão, o fato de esse conhecimento ser compartilhado pela equipe e reafirmado pela maioria garante maior segurança na deliberação. Esse caráter coletivo é apoiado por Gracia ${ }^{17}$, quando menciona a importância da deliberação coletiva, com discussão de diversos pontos de vista e justificações para enriquecer o diálogo. Contudo, ao mesmo tempo, transmite-nos a ideia de que, de certa forma, essa divisão de responsabilizações aliviaria a responsabilidade individual mediante o embate moral.

Percebemos que, em todas as tentativas de valorização da autonomia, há menção às questões jurídicas:

“[...] Se ele não quiser receber qualquer tratamento que qualquer profissional estiver propondo, a gente tem que respeitar essa autonomia do paciente. [...] Então se ele expressa esse desejo de não ser intubado e não receber nenhum tipo de tratamento que prolongue a vida dele, eu acho que ele tem total autonomia de decidir por isso. [...] Mas deveria estar documentado. Isso, porque caso contrário também poderia reverter a situação contra os profissionais. [...] Os profissionais tem que ser prudentes tanto olhando a questão do paciente quanto olhando também a questão deles, assim". (D10)

Podemos reconhecer, no primeiro trecho, a preocupação do discente com a liberdade do sujeito em decidir sobre sua própria vida, todavia, a imperatividade da regulamentação legal para que isso ocorresse foi maior que esse princípio prima facie. Assim, a realização do procedimento somente com documento por escrito e devidamente assinado correlaciona-se com um grande caráter legalista para assegurar a autonomia do paciente, e demonstra certa heteronomia na tomada de decisão, visto que a exigência documental foi colocada como garantia de uma não punição. Tal caráter legalista é ainda mais enfático na fala seguinte:

"Eu não vou responder criminalmente por isso". (D5)

Zoboli ${ }^{18}$ questiona que, muitas vezes, os profissionais reduzem às questões técnicas e jurídicas, quando, na verdade, são conflitos de valores. E, com isso, oferecem soluções baseadas apenas em determinações técnicas e legais.

Não colocar os conflitos de valores no âmbito da ética, que é seu verdadeiro espaço, acaba por comprometer a deliberação e as decisões prudentes; parte-se de um equívoco e chegase a outro, mas, sem dúvida ameniza-se a angústia que os profissionais de saúde sentem ao terem de lidar com problemas éticos, pois o que deve ser feito já vem definido por instâncias exteriores, consideradas superiores e que determinam o que deve ser feito [...]. Não resta ao profissional, senão acatar tais mandos externos, em uma atitude heterônoma que está na base das falácias da Bioética. ${ }^{18}$ (p. 284) 
Convencionalmente, não existe obrigatoriedade do documento, e a existência deste não exime de responsabilidade ou culpa ${ }^{17}$. É fato que o consentimento informado é de suma importância como recurso jurídico concreto e palpável. Por outro lado, "consentimento livre e esclarecido é mais que obter um documento assinado. Envolve troca mútua de informações, compreensão, confiança e consentimento entre o paciente e o [profissional]"19 (p. 9).

"Entendemos que o consentimento esclarecido deve ser componente de uma relação ética de cuidado, na qual há reconhecimento do direito da pessoa em fazer suas escolhas baseadas em seus próprios valores" ${ }^{20}$ (p. 158). "Esse respeito envolve ação respeitosa, e não meramente atitude respeitosa"14 (p. 143).

Acreditamos que a essência do consentimento não está na imposição da mera burocratização, pois são necessárias mais que obrigações de não intervenção nas decisões das pessoas. Em contrapartida, devemos incluir obrigações para sustentar as capacidades dos outros para escolher autonomamente, diminuindo temores e outras condições que arruinarem sua autonomia. O respeito pela autonomia implica tratar as pessoas de forma a capacitá-las a agir autonomamente ${ }^{14}$.

Outros estudantes acrescentam que concordam com a intubação desde que o profissional converse com a família. Acreditaram que desta forma, a solução permite cuidar do paciente e ter o consentimento dos familiares.

Um entrevistado defende que, no caso de impedimento do paciente, o consentimento informado deve ser dado pela família, por meio da decisão substituta, que é a tomada de decisões no lugar do paciente não autônomo ou cuja autonomia é incerta ${ }^{14}$.

Diante dessa possibilidade, pode haver diversos impasses, por exemplo: O paciente tinha capacidade decisória com discernimento? As evidências são confiáveis para determinar a preferência do paciente? O mesmo foi devidamente esclarecido para tomar sua decisão conscientemente? Até que ponto o decisor não usará os seus valores como prerrogativa para decidir sobre a vida do outro? É lícito anular as diretrizes de ação deixadas pelo próprio paciente anteriormente autônomo, em prol dos possíveis benefícios dos tratamentos? A decisão do substituto representa integralmente a decisão do próprio paciente?

Juridicamente, "a recusa à tratamentos médicos ou intervenções cirúrgicas, embora bastante discutida na doutrina, deve ser respeitada, salvo se colidir com a vida, hermeneuticamente considerada como um bem maior"21 (p. 35). Destarte, a vida é considerada um direito fundamental, salvaguardado pela constituição brasileira.

Constitucionalmente, também há garantia do respeito à dignidade da pessoa humana. Por conseguinte, como garantir a dignidade, se os valores morais e religiosos de uma pessoa estão sendo desrespeitados? "Podemos entender que a dignidade está também em ter autonomia de decidir mediante seus valores, sobre o curso de sua vida, mas também, pela sua morte digna, se for o caso" 20 (p. 150).

De acordo com o Código de Ética de Fisioterapia22, existe respaldo ético para ambos os cursos de ação. No Artigo 14, é dever fundamental do fisioterapeuta respeitar o princípio bioético de autonomia do paciente de decidir sobre sua pessoa e seu bem-estar. Também é dever "respeitar a vida humana desde a concepção até a morte, jamais cooperando em ato em que voluntariamente se atente contra ela, ou que coloque em risco a integridade física, psíquica, moral, cultural e social do ser humano"21 (p. 85). O Artigo 10 menciona, ainda, que é proibido ao fisioterapeuta recomendar, prescrever e executar tratamento, ou nele colaborar, quando praticado sem o consentimento formal do paciente ou de seu representante legal ou responsável, quando se tratar de menor ou incapaz.

Gracia $^{17}$ defende que o principal direito dos doentes é o do consentimento informado, que é o símbolo da passagem do absolutismo médico clássico à teoria liberal do exercício da profissão. É a garantia jurídica do direito à liberdade no tema de gestão do corpo. De acordo com o que defendemos como cuidado integral e ético, o consentimento ultrapassa os limites jurídicos, mas incumbe o paciente 
a se tornar ativo no seu processo de tomada de decisão, no juízo do diagnóstico, prognóstico e terapêutico ${ }^{17}$.

Como defendemos anteriormente, é preciso que se estabeleça um canal de comunicação entre profissional e paciente, e que este receba todas as informações acerca do seu quadro clínico, prognóstico, riscos e benefícios, para que a decisão seja consentida consciente e autonomamente ${ }^{22}$.

Para finalizar as discussões acerca do dilema apresentado e tendências apontadas pelos discentes, gostaríamos de ressaltar que "não há comunicação adequada sem apoio emocional"17 (p. 316). Esse apoio deve enfatizar que o profissional de saúde tem de abandonar o paternalismo e respeitar a capacidade de autogoverno do paciente. "Não se pode fazer as pessoas felizes à força. Ou melhor, há que deixar que cada um viva de acordo com sua ideia de felicidade"17 (p. 313).

Por conseguinte, acreditamos que a tomada de decisão ética não deve ser analisada somente sob a seara dos valores inerentes aos profissionais, mas é imperativo que haja valorização do outro e responsabilização conjunta por essa relação. Nessa perspectiva, apoiamos a proposta de uma ética do cuidado, que fundamente a tomada de decisões ética em saúde, de forma que a moralidade seja referente à responsabilidade do cuidar advinda do vínculo para com os outros ${ }^{20}$.

\section{Considerações finais}

Mediante o dilema moral proposto, muitos entrevistados relataram a importância de se respeitar a vontade do paciente. Mas, observamos que essa autonomia - prima facie - passou a ser desconsiderada quando o paciente já não é capaz de se expressar com lucidez. É nesse momento que o conhecimento acerca "do que é melhor para o paciente" - na opinião do profissional - e o dever moral de fazer o bem (beneficência) - característico do pensamento hipocrático - ofereceram uma possibilidade de conduta defensável.

Quando ponderaram sobre a autonomia do paciente, observamos forte correlação entre a sua garantia e a necessidade de um consentimento informado e devidamente documentado, primeiramente, pelo próprio paciente, e, em caso de não lucidez, pelos familiares diretos. Isso denota a forte referência legalista na garantia da autodeterminação do paciente.

A beneficência parece ser um valor de grande relevância para os entrevistados, tendo maior validade nas tomadas de decisão em detrimento da autonomia do paciente. A partir do que foi relatado pelos discentes de fisioterapia, é provável que o valor intrínseco da vida somado ao caráter hipocrático beneficente possam fundamentar a moralidade do cuidado.

Concluímos, também, que a tomada de decisão em fisioterapia valoriza, em supremacia, os aspectos técnicos aos éticos, o que gera a necessidade de repensarmos a formação, para que os futuros fisioterapeutas possam cuidar reconhecendo e valorizando o indivíduo, em uma inter-relação ética e humana.

Pensar somente nas condições clínicas do paciente seria limitar o escopo de visão de todos os componentes dessa "clínica", do cuidado integral à saúde do ser humano. É preciso questionar, refletir, analisar e ponderar todos os aspectos envolvidos; sejam eles físicos, psíquicos, ético/morais, sociais, culturais e religiosos.

Por fim, depreendemos que há deficiência no referencial bioético dos discentes frente aos conflitos presentes na relação de cuidado. Faz-se necessário avançarmos com a finalidade de se ultrapassarem as questões deontológicas e de cunho legalista, capacitando os discentes para as diversas decisões morais que o cuidado fisioterapêutico contempla. Nesse sentido, acreditamos que a bioética faz-se relevante no intuito de fornecer ferramentas para as ações em saúde, aprimorando as competências e habilidades éticas e morais dos discentes e futuros fisioterapeutas. 


\section{Colaboradores}

Talita Leite Ladeira participou da elaboração, condução da pesquisa e análise dos dados, concepção e redação do artigo. Aluísio Gomes da Silva Junior orientou a pesquisa e participou da revisão crítica do texto. Lilian Koifman participou da revisão e redação final do artigo.

\section{Referências}

1. Silva AL, Ciampone MHT. Um olhar paradigmático sobre a Assistência de Enfermagem: um caminhar para o cuidado complexo. Rev Esc Enferm USP. 2003; 37(4):13-23.

2. Almeida AJ, Guimarães RB. O lugar social do fisioterapeuta brasileiro. Fisioter Pesqui. 2009; 16(1):82-8.

3. Bispo Junior JP. Formação em fisioterapia no Brasil: reflexões sobre a expansão do ensino e os modelos de formação. Hist Cienc Saude-Manguinhos. 2009; 16(3):655-68.

4. Ghizoni AC, Arruda MP, Tesser CD. Integrality: the perspective of physiotherapists from a medium-sized town. Interface (Botucatu). 2010; 14(35):825-37.

5. Silva ID, Silveira MFA. A humanização e a formação do profissional em fisioterapia. Cienc Saude Colet. 2011; 16 Supl 1:1535-46.

6. Gallo DLL. A Fisioterapia no Programa de Saúde da Família: percepções em relação à atuação profissional e formação universitária [dissertação]. Londrina (PR): Universidade Estadual de Londrina; 2005.

7. Swisher LL. A retrospective analysis of ethics knowledge in physical therapy (1970-2000). Phys Ther. 2002; 82(7):692-706.

8. Purtillo RBA. Time to harvest, a time to sow: ethics for a shifting landscape. Phys Ther. 2000; 80(11):1112-9.

9. Parecer CNE/CES 1210/2001. Diretrizes Curriculares Nacionais dos Cursos de Graduação em Fisioterapia, Fonoaudiologia e Terapia Ocupacional. Diário Oficial da União. 10 Dez. 2001.

10. Lorenzo CFG, Bueno GTA. A interface entre bioética e fisioterapia nos artigos brasileiros indexados. Fisioter Mov. 2013; 26(4):763-75.

11. Badaró AFV, Guilhem D. Bioética e pesquisa na Fisioterapia: aproximação e vínculos. Fisioter Pesqui. 2008; 15(4):402-7.

12. Resolução $n^{\circ} 466$, de 12 de dezembro de 2012. Aprova normas regulamentadoras de pesquisas envolvendo seres humanos. Diário Oficial da União. 13 Jun. 2013.

13. Bardin L. Análise de conteúdo. São Paulo: Edições 70; 2011.

14. Beauchamp TL, Childress JF. Princípios da ética biomédica. 5a ed. São Paulo: Loyola; 2002.

15. Siqueira Batista R. Às margens do Aqueronte: finitude, autonomia, proteção e compaixão no debate bioético sobre a eutanásia [tese]. Rio de Janeiro (RJ): Escola Nacional de Saúde Pública Sergio Arouca; 2006.

16. Schramm FR. Vida: sacralidade e/ou qualidade? Cad Atual Debate. 1995; 34(1):44-69.

17. Gracia D. Pensar a Bioética: metas e desafios. São Paulo: Loyola; 2010.

18. Zoboli ELCP. Deliberação: leque de possibilidades para compreender os conflitos de valores na prática clínica da atenção básica [tese]. São Paulo (SP): Escola de Enfermagem, Universidade de São Paulo; 2010. 
19. Tavares MR. Aspectos bioéticos do consentimento livre e esclarecido. Rev Bras Cir Cabeça Pescoço. 2003; 31(2):7-11.

20. Ladeira TL. Significados, sentidos e vozes do cuidado integral: aspectos bioéticos na formação do fisioterapeuta. Niterói. [dissertação]. Niterói: Universidade Federal Fluminense; 2014.

21. Consalter ZM, Jaremczuk, P. Direito à vida versus recusa ao tratamento vital. Prism. Jurid. 2010; 9(1):35-53.

22. Resolução n 424, de 8 de julho de 2013. Estabelece o Código de Ética e Deontologia da Fisioterapia. Diário Oficial da União. 1 Ago 2013.

Ladeira TL, Silva Junior AG, Koifman L. Fundamentos éticos en la toma de decisión de discentes de fisioterapia. Interface (Botucatu). 2017; 21(62):675-85.

La toma de decisión clínica debe incluir aspectos técnicos y éticos. Es necesario reconocer los conflictos éticos y comprender los valores morales envueltos para, finalmente, proporcionar respuestas eficientes a las cuestiones éticas presentes en la praxis. Este estudio cualitativo descriptivo tiene como objetivos comprender la percepción de los discentes de fisioterapia sobre los valores morales que deben regir las acciones de cuidado e identificar los fundamentos éticos que sirven de base a la toma de decisiones. En la investigación participaron 13 discentes de fisioterapia de una universidad federal brasileña. Se realizaron entrevistas semi-estructuradas individuales, con aplicación de un dilema moral hipotético relacionado con la práctica profesional. Observamos deficiencia en el referencial bioético de los discentes antes los conflictos expuestos. Por lo tanto, existe la necesidad de que repensemos la formación, con el fin de fomentar la toma de decisiones más conscientes y resolutivas en salud.

Palabras clave: Bioética. Toma de decisiones. Fisioterapia.

Submetido em 18/04/16. Aprovado em 26/08/16. 
